Gut, 1964, 5, 285

\title{
Gastric epithelium in the duodenum
}

\author{
A. H. JAMES \\ From the Medical Unit, Cardiff Royal Infirmary, Cardiff, Wales
}

EDITORIAL SYNOPSIS It has been found that a 'gastric' type of epithelium tends to develop in the first part of the duodenum in patients with duodenal ulceration and is found in the second part of the duodenum in a patient with the Zollinger-Ellison syndrome. It is likely that 'gastric' epithelium appears when the duodenal acidity is high and it is resistant to ulceration.

The stomach is normally lined by one kind of epithelium and the duodenum by another. Islands of intestinal epithelium have long been known to occur in the stomach, particularly when gastric acidity is low: this paper describes islands of gastric epithelium in the duodenum; they are especially common when gastric, and hence duodenal, acidity is high. These anomalies mirror each other, and the conditions which bring them about throw light, it will be suggested, upon the pathogenesis of peptic ulceration and the determination of its site.

Taylor (1927), reviewing heterotopia in the alimentary tract, described two instances of gastric epithelium in the duodenum. They were found among 150 necropsies, and were recognizable as slightly raised patches. Histological examination showed these to be covered by well-preserved gastric epithelium and to contain gastric glands with both chief and parietal cells; Brunner's glands were absent from the patches. In both cases the patches were found in the first part of the duodenum near the pylorus, and in one there was a duodenal ulcer. The presence of gastric glands places these patches in a different category from those described in this paper, where only the epithelium was abnormal.

Patzelt (1936) reviewed the histology of the pyloro-duodenal region in animals and man and quoted descriptions which showed that the line of epithelial demarcation was not always sharp, there being islands of intestinal epithelium on the gastric side of the pylorus and, much more rarely, of gastric epithelium on the intestinal side. His article contains an illustration of one such 'Magenepithelinsel' found in the duodenum of a woman; the island appears to cover an inflammatory polyp containing a lymph follicle; no gastric glands were present.

Misplaced gastric epithelium has not been mentioned in any of the studies of duodenal mucosa in patients with duodenal ulcer. Puhl (1927), who obtained mucosa from operation specimens, found that the epithelium was either normal or more often undifferentiated, the cells having deeply stained nuclei and cytoplasm, and showing multiple layering; goblet cells tended to be lacking in such cases. The published photomicrographs are not of sufficient magnification to exclude the presence of gastric epithelium. Shiner (1957) took mucosal specimens from the duodenum by an aspiration biopsy tube; the biopsies were taken from the first or second part of the duodenum, and the histological study of them by Doniach and Shiner (1957) does not distinguish between these different sites of origin. In most of the biopsies the mucosa was normal and the epithelium well preserved. In some there was distortion or atrophy of the villi, and in these there might be abnormalities of the epithelial cell nuclei and an increase in the number of goblet cells.

Aronson and Norfleet (1962) took biopsies from the duodenum using the Crosby-Kugler capsule. In normal subjects and in a majority of patients with duodenal ulcer the mucosal histology was undisturbed; in four of the 18 patients the villi were blunted or flattened; abnormalities of the epithelial cells are not mentioned, but the photomicrographs do not serve to exclude them.

James (1963) described a patient in whom the diagnosis of Zollinger-Ellison syndrome was suspected but not proved: there was a high output of acid by the unstimulated stomach. Biopsies were taken at operation from the mucosa of the second part of the duodenum. There was an extensive abnormality of the surface epithelium, the cells resembling gastric cells. It was to assess the significance of this finding that the present survey of duodenal histology was undertaken.

Gastric epithelial cells have appeared in the duodenum of the cat (Florey and Harding, 1935) and of the pig (Florey, Jennings, Jennings, and O'Connor, 1939) in experiments which may help to explain the same anomaly in humans, and which will 
therefore be discussed in the light of the findings now to be presented.

\section{METHODS}

Mucosa was obtained at operation by one of two methods, according to the procedure being undertaken. At partial gastrectomy the freshly removed tissue was opened along the greater curvature, and the pylorus identified by the fold of redundant mucosa which marks it; a strip of duodenal mucosa was cut off and immediately placed in formol-saline. If a pyloroplasty and vagotomy was being done, a small piece of duodenal mucosa was excised after the pylorus had been identified from the opened duodenum.

There were 10 patients with duodenal ulcer, one of whom also had a gastric ulcer, four with pyloric ulcer, eight with gastric ulcer, and 10 with gastric carcinoma. No comparable material has been obtained from cases of the Zollinger-Ellison syndrome, but tissue from the second part of the duodenum in one such case is described.

Sections $6 \mu$ thick were stained with haematoxylin and eosin and with periodic acid and Schiff's reagent (P.A.S.). The sections were examined in random order without knowledge of the diagnosis. Particular attention was paid to the surface epithelium, and the prevalence of abnormal cells recorded as described below. The size and shape of the villi were noted, together with the degree of cellular infiltration of the lamina propria.

\section{RESULTS}

VILLOUS ANATOMY Some of the sections showed normal intestinal villi. More often, however, the villi were shorter and blunter than those found lower down the intestine, and in some cases the villi were completely atrophic. Villous atrophy was common in duodenal ulcer, less common in pyloric ulcer, and rare in gastric ulcer or cancer.

SURFACE EPITHELIUM In all sections a majority of the villi were covered with epithelial cells of normal appearance, with a brush border and prominent mitochondria. These cells were interspersed with goblet cells in normal numbers and concentrated near the bases of the villi. With P.A.S. the brush border is seen as a thin line of even width at the free border of the cell. Commonly the epithelial cells were shrunken and displayed the characteristics described by Puhl (1927) and mentioned in the introduction: this abnormality was most prominent when there was villous atrophy.

A particular search was made for gastric epithelial cells, that is, columnar cells lacking a brush border and containing a mucous droplet of variable size in their distal portion. Such cells were often seen, and examples are shown in Figures 1, 2, and 3. They were most easily recognized in P.A.S.-stained sections and may easily be overlooked in sections stained with haematoxylin and eosin (contrast Fig. 4 with Fig. 3). The mucous droplet stains exactly the same colour with P.A.S. as does the similar droplet in gastric epithelium, whereas other P.A.S.-positive material in the section, such as the contents of Brunner's glands or of the goblet cells, stained with a distinctly bluer tint.

The mucous droplet varied in size from a small accumulation at the distal end of the cell up to a mass which filled nearly the whole cell, and appeared to displace and deform the nucleus. Under high magnification the mass of P.A.S.-staining material seemed to be made up of smaller droplets, and separate droplets could be seen forming on the basal side of the main mass and seemingly being added to it. These cells were of the same height as their normal neighbours, but tended to be narrower and to have more deeply staining cytoplasm. The brush border and mitochondria were lacking.

Gastric epithelial cells were never seen singly but always in contiguous groups of at least three or four and usually many more. They were most commonly found at or near the tips of villi; sometimes they were seen at the sides of villi and occasionally in the crypts.

They were more commonly seen on villi which were stunted, and when, as commonly happened, villous atrophy occurred patchily in a section gastric cells were more prevalent on the short villi. Groups of them were, however, seen on normal villi; that shown in Fig. 5 was the only one found in 101 villi in a section from a patient with gastric ulcer. In a few cases, such as that illustrated in Fig. 6, they covered small polyps.

These cells were obviously not goblet cells. Their shape differed from that of a goblet cell, and their mucous droplet lacked the bluish tint and reticularity which were characteristic of goblet cells. The distribution of goblet cells was the reverse of gastric cells in that they were most common near the bases of the villi and usually absent from the tips. Another point of distinction was that goblet cells were nearly always isolated; even when very numerous they were separated from each other by normal intestinal cells.

The transition from intestinal cell to gastric cell was usually sudden; a cell was clearly of one sort or the other (Figs. 1, 3 and 5). No mitoses were seen in gastric cells: as is usual in the gut mitoses were deep in the crypts where the cells are relatively undifferentiated.

PREVALENCE OF GASTRIC EPITHELIUM In order to compare the prevalence of gastric epithelium in the different groups of patients the villi on each section 


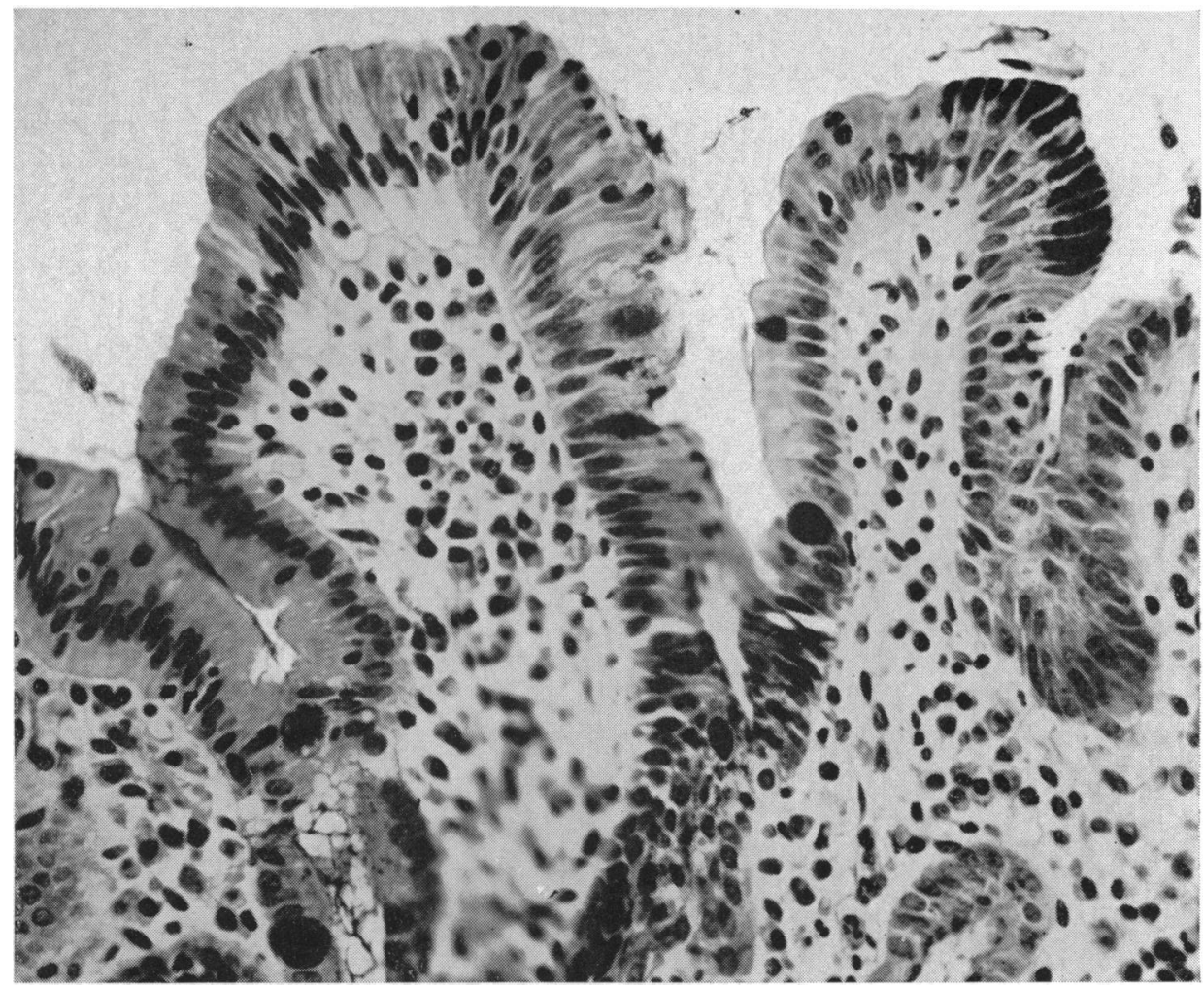

FIG. 1. From a 28-year-old man with duodenal ulcer. The stunted villus at the right centre carries a patch of gastric epithelium containing 14 cells near its tip. Many of the other epithelial cells in this section are degenerate $($ P.A.S. $\times 400)$.

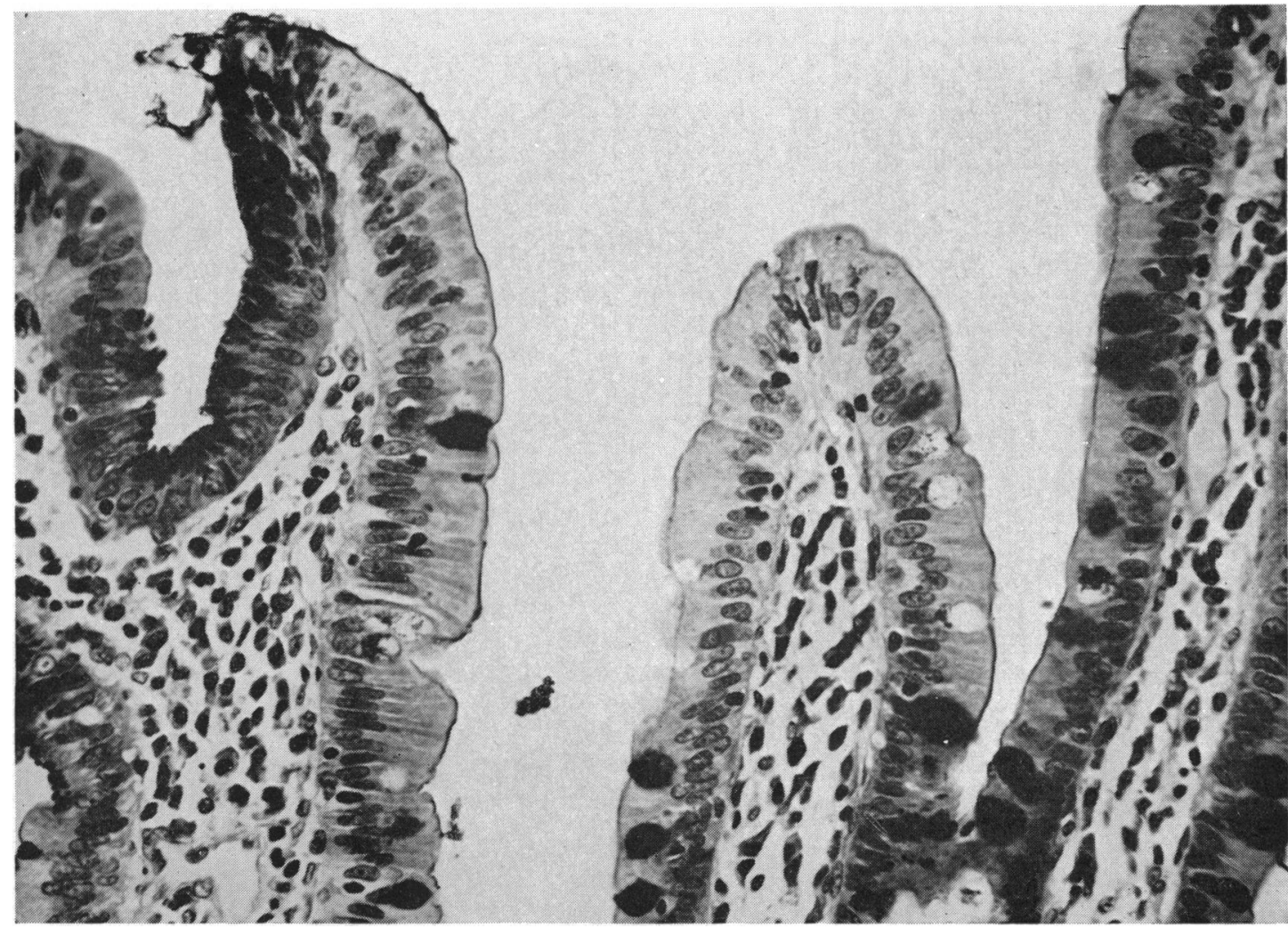

FIG. 2. From a 61-year-old man with duodenal ulcer. The villus at the left carries near its tip a patch of gastric cells some of which are cut tangentially. The brush border of the neighbouring cells can be seen to reach the edges of the patch (P.A.S. $\times$ 400). 


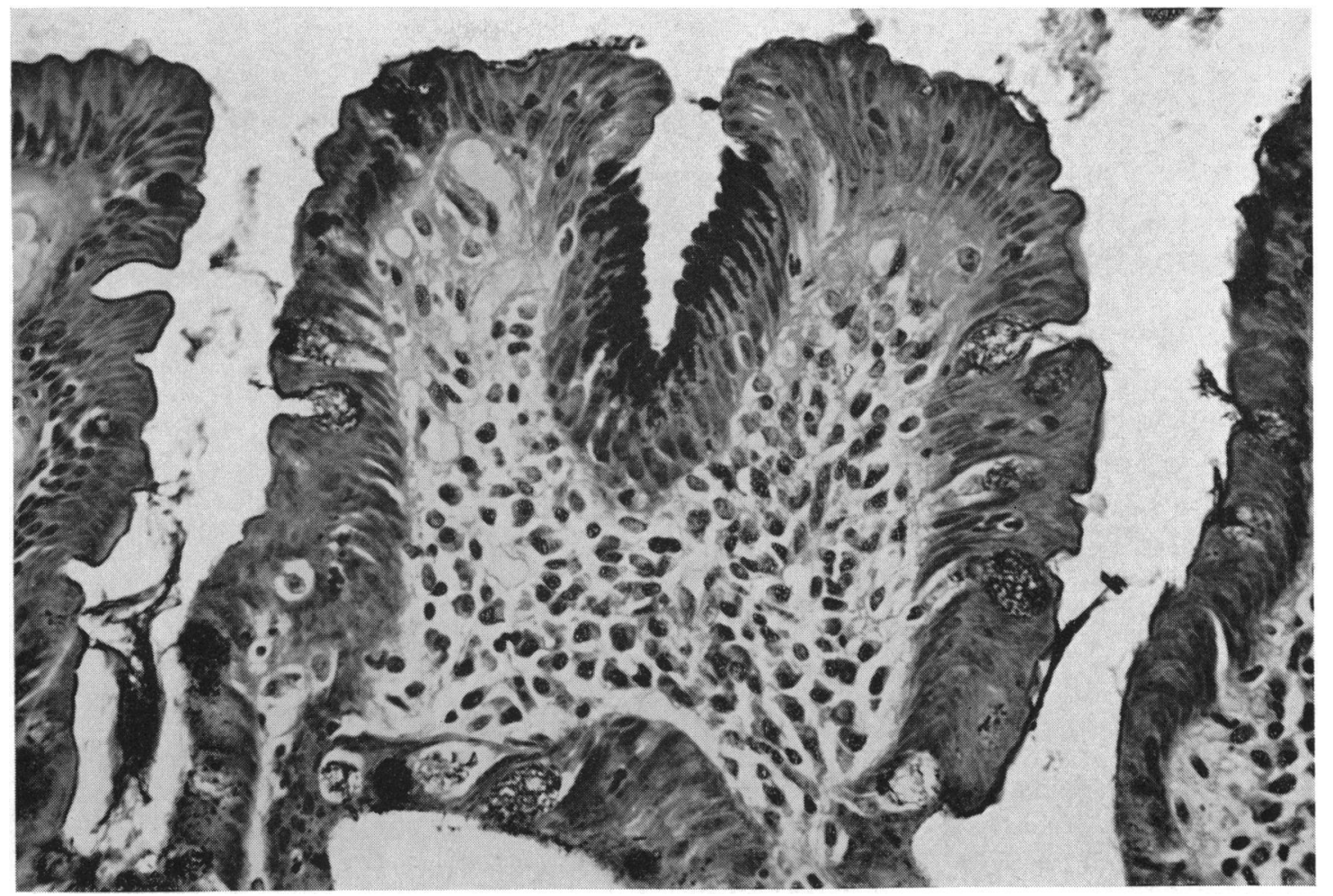

FIG. 3.

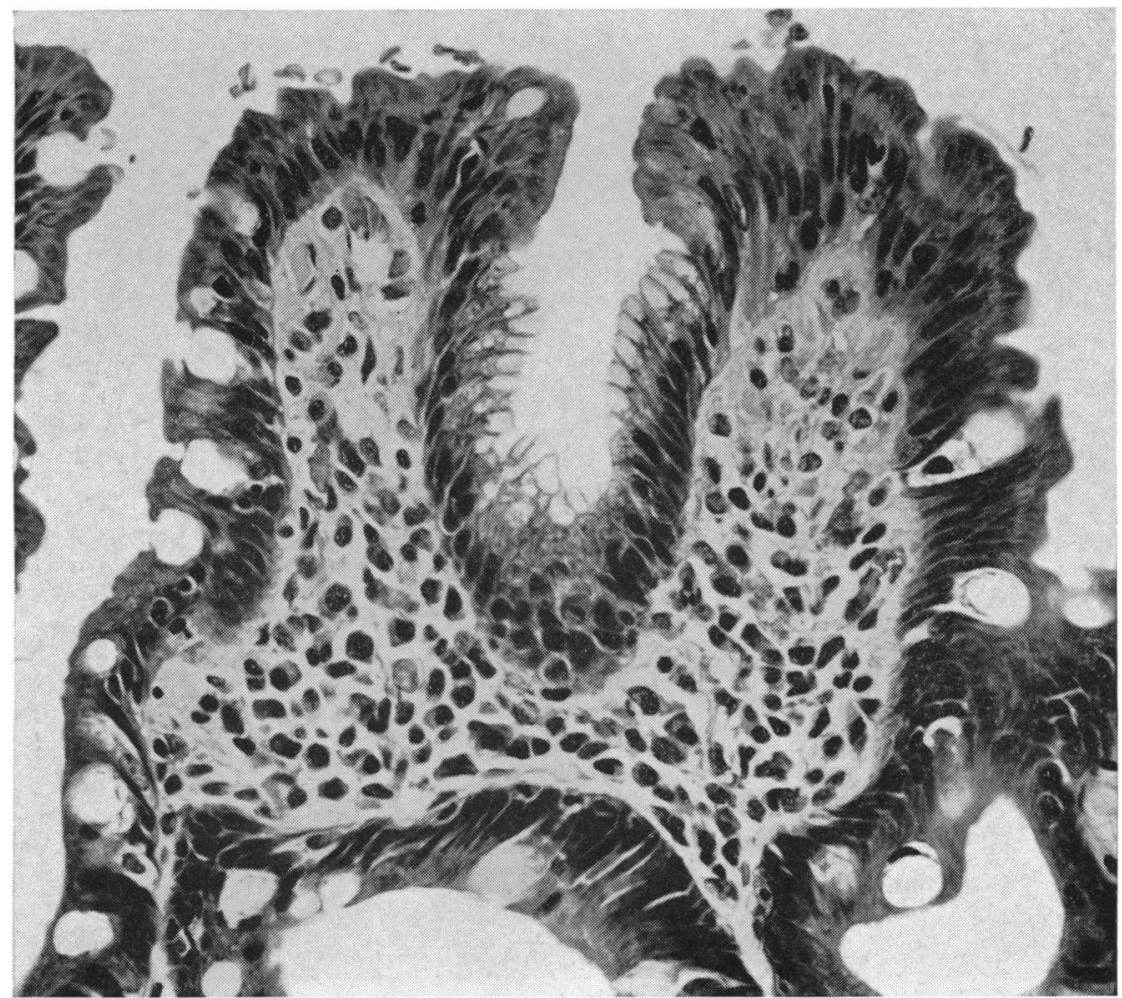

FIG. 3. From a 51-yearold woman with pyloric ulcer. A cleft in this villus contains a patch of gastric epithelium (P.A.S. $\times 400)$.

FIG. 4. Same section as Fig. 3, showing that haematoxylin and eosin do not emphasize gastric cells as does P.A.S. (Haematoxylin and eosin $\times 400)$.

FIG. 4. 


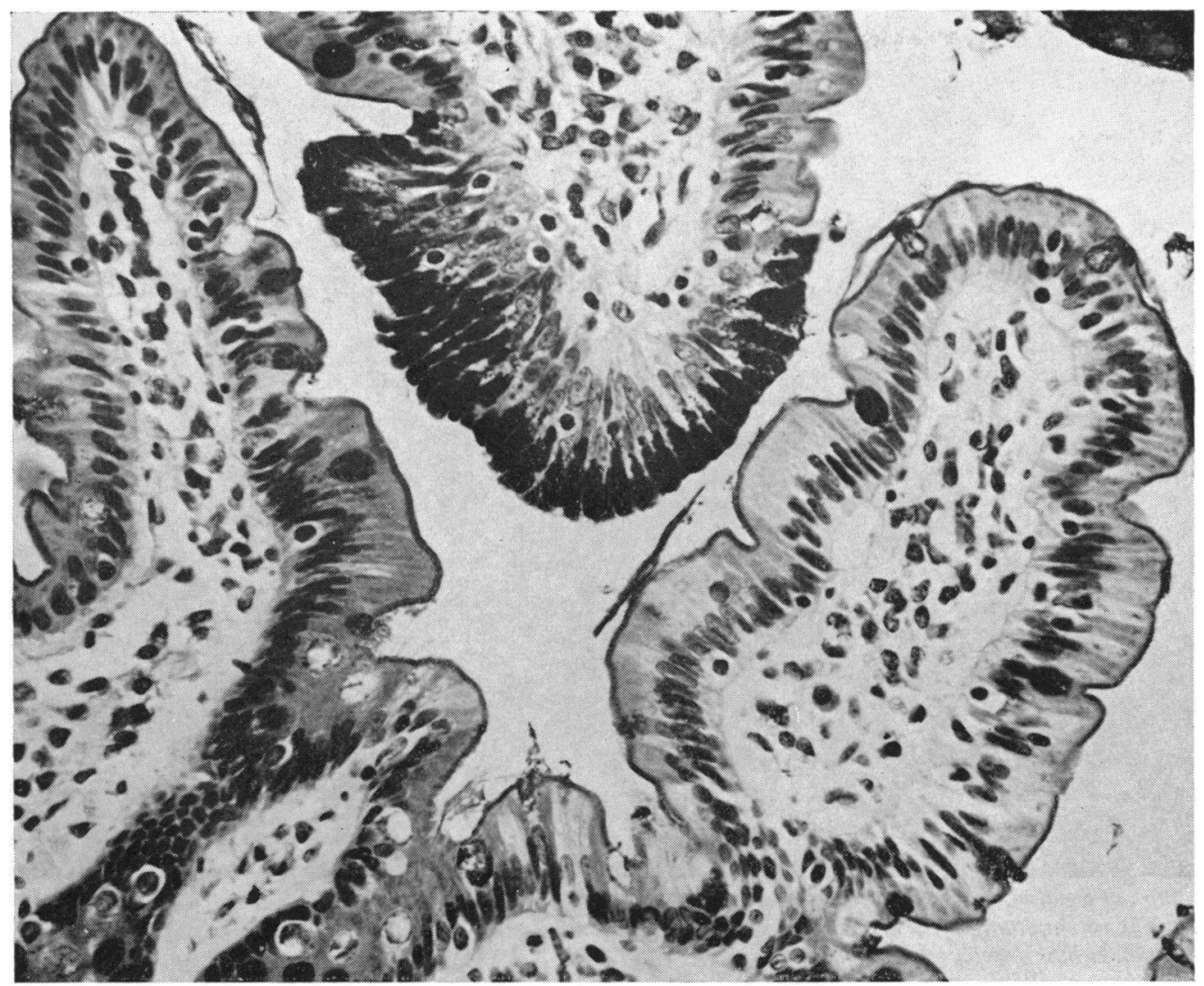

FIG. 5. From a 45-year-old man with gastric ulcer. One villus, which is cut tangentially, carries a patch of gastric epithelium. All the 101 villi on this section were of normal size $($ P.A.S. $\times 400)$.

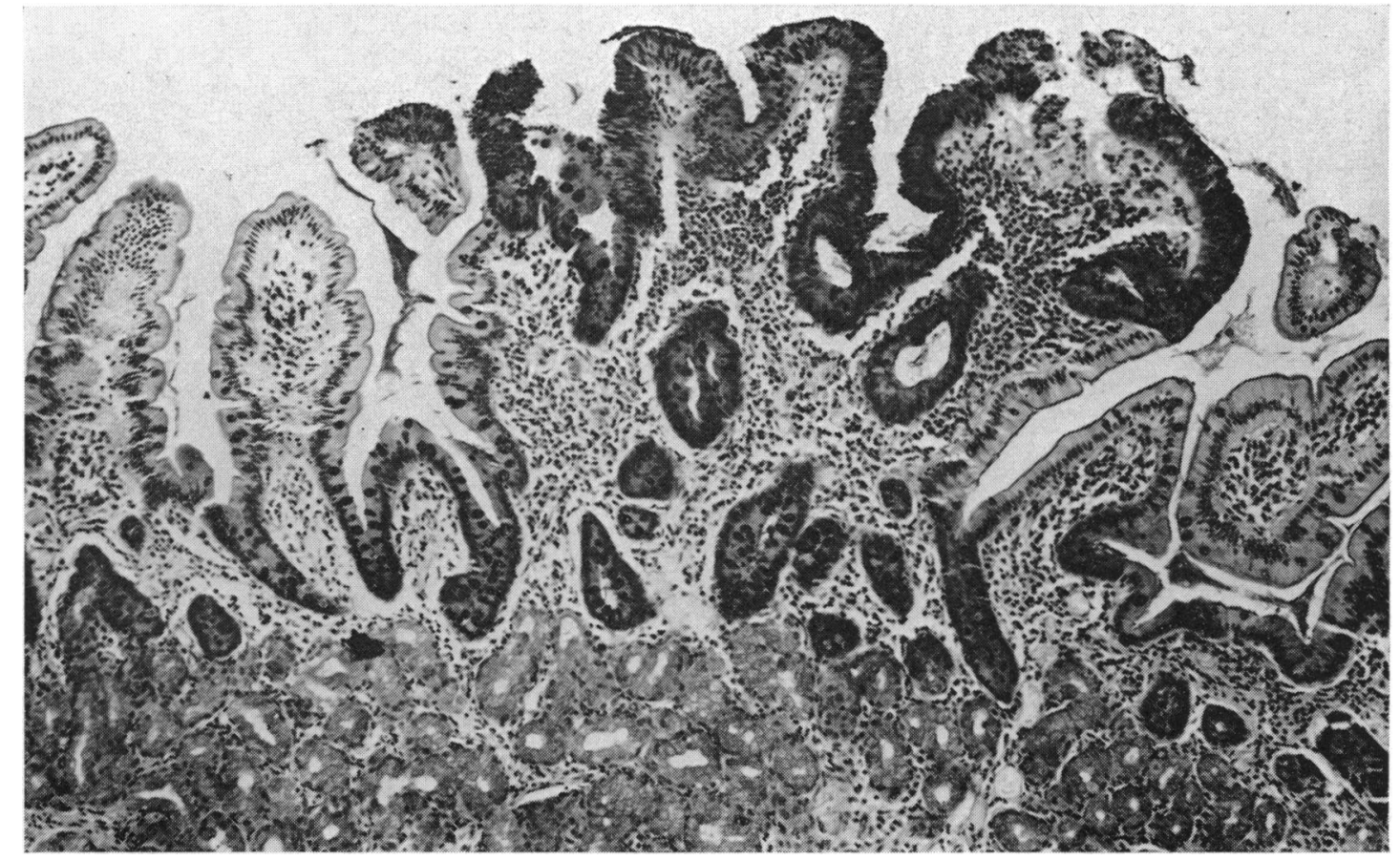

FIG. 6. From a 66-year-old man with carcinoma of the stomach. This small polyp is largely covered with gastric epithelium; there is increased cellular infiltration of the lamina propria $(P . A . S . \times 100)$. 


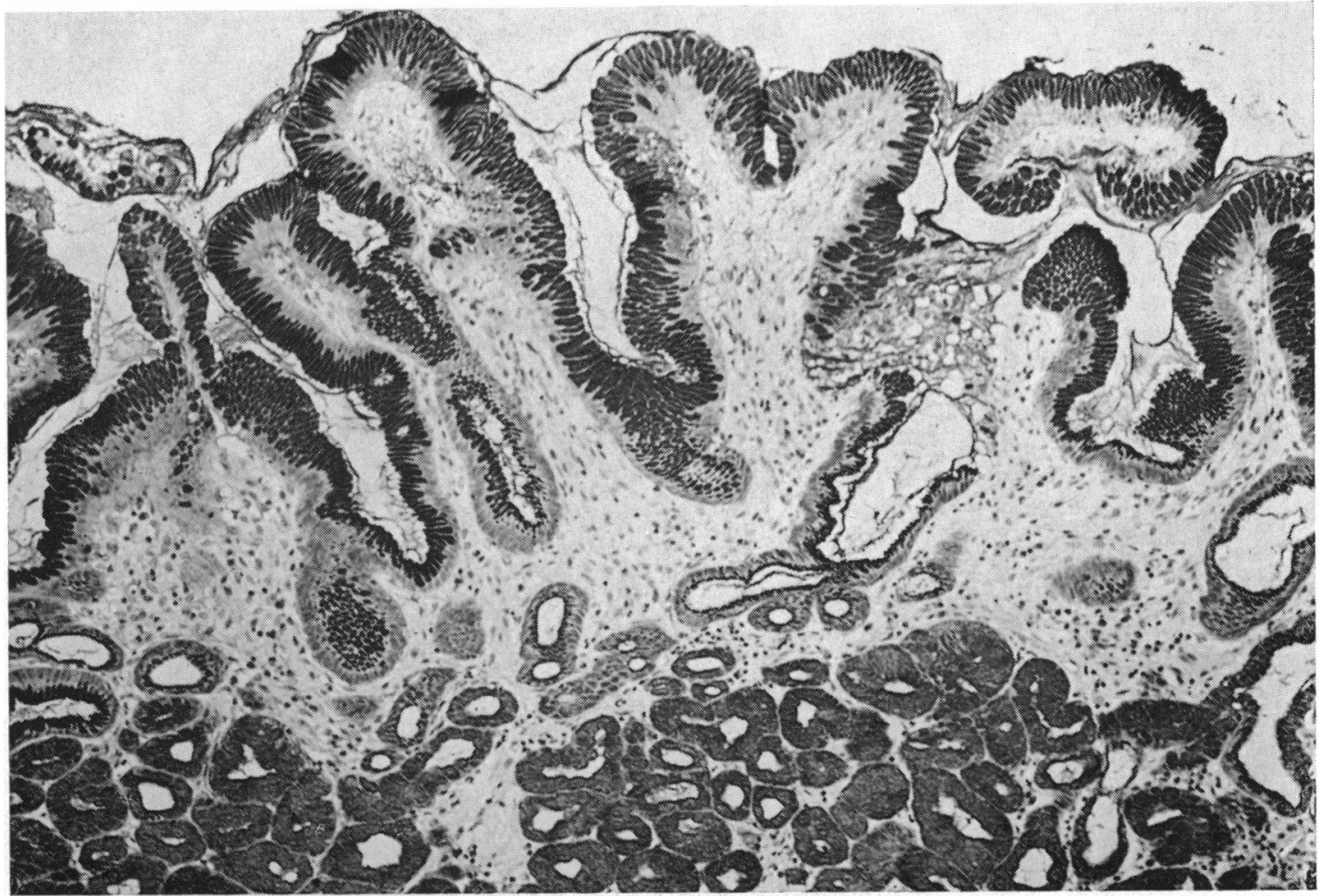

FIG. 7. Part of a polyp taken from the second part of the duodenum of a 29-year-old woman with the Zollinger-Ellison syndrome. The rather stunted villi are covered with well-developed gastric epithelium which extends into the short crypts. The epithelium is best developed at the summits of the villi $($ P.A.S. $\times 135)$.

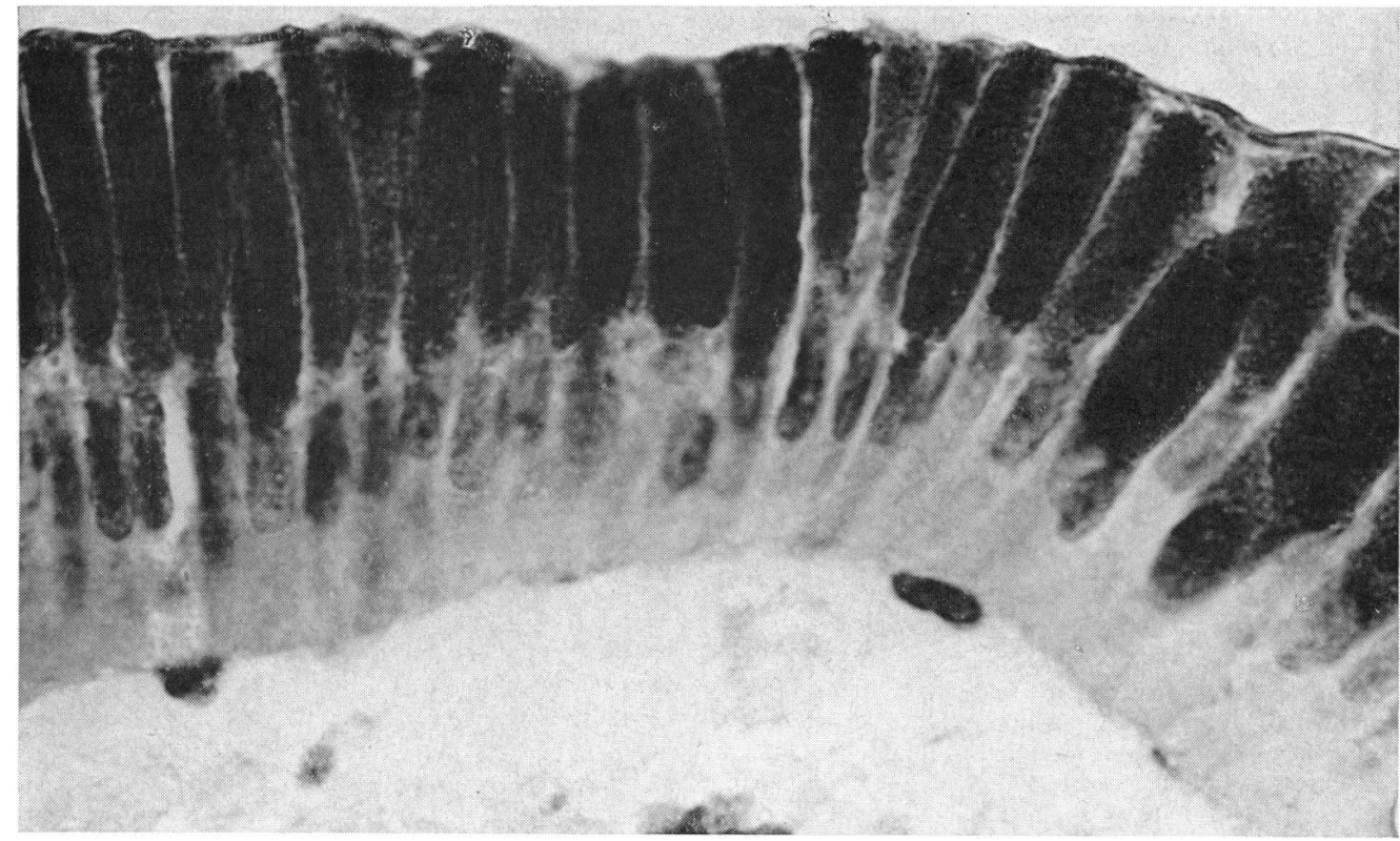

FIG. 8. Same section as Fig. 7, showing 'gastric' epithelial cells at higher magnification. The mucous droplets can be seen to be made up of smaller droplets or particles. The membrane covering the luminal border of the cells is probably precipitated mucus $($ P.A.S. $\times 1,400)$. 
TABLE I

PREVALENCE OF VILLI WITH GASTRIC EPITHELIUM IN EACH DIAGNOSTIC GROUP

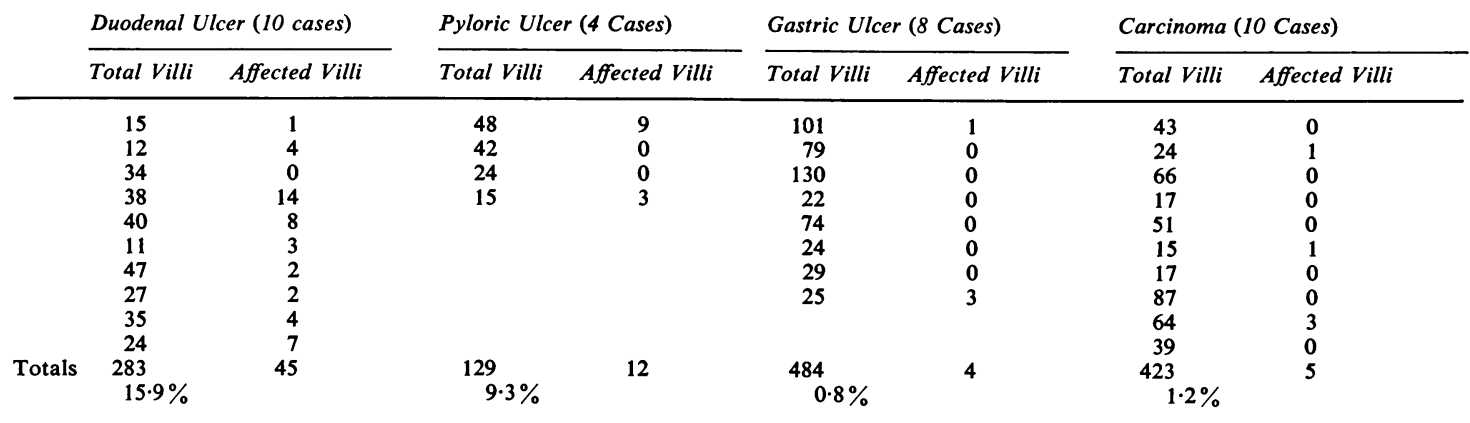

were counted, and then the number of those which had any gastric epithelium on them. No attempt was made to assess the size of the individual patches of gastric epithelium, although it usually happened that when the patches were numerous they were also large. The results are given in Table $I$ and show a striking disparity between the different groups of patients. In only one of the 10 patients with duodenal ulcer was gastric epithelium not seen, and the mean proportion of affected villi was $15.9 \%$. Conversely, only a minority of patients with gastric ulcer or cancer showed gastric epithelium, and in these the proportion of affected villi was small: the average proportions for the whole groups were $0.8 \%$ and $1.2 \%$ respectively. The small group of patients with pyloric ulcer lay intermediately.

There was a greater prevalence of gastric epithelium in women. Table II shows the prevalences separately for each sex and diagnostic group; in all groups prevalences were greater in women, and the total prevalence for the 15 women was $6.7 \%$ as against $3.0 \%$ for the 17 men, even though there were two cases fewer of duodenal ulcer among the women.

The prevalence of affected villi was greater where there was villous atrophy; not only were these two features most prominent in duodenal ulcer and least in gastric ulcer or cancer, but within the duodenal ulcer group there was a tendency for villous atrophy and gastric epithelium to be associated.

Apart from site of ulcer, sex, and villous atrophy, no other independent quantity has been found to be correlated with gastric epithelium. There was, of course, association with such features as ABO blood group, which are themselves associated with site of ulcer, but within each diagnostic group there was no association of blood group with the prevalence of gastric cells, and the same was true of age and length of ulcer history.

One possible source of artefact must be considered, namely, the effect of using different methods to
TABLE II

PREVALENCE OF VILLI WITH GASTRIC EPITHELIUM IN EACH DIAGNOSTIC GROUP AND FOR EACH SEX

Men Women

\begin{tabular}{lrr}
\hline Duodenal ulcer & 6 & 4 \\
Cases & 147 & 136 \\
Total villi & 16 & 29 \\
Affected villi & & \\
& 2 & 2 \\
Pyloric ulcer & 66 & 63 \\
Cases & 0 & 12 \\
Total villi & & \\
Affected villi & & \\
Gastric ulcer & 3 & 5 \\
Cases & 154 & 330 \\
Total villi & 1 & 3 \\
Affected villi & & \\
Curcinoma & 6 & 4 \\
Cases & 235 & 188 \\
Total villi & 1 & 4 \\
Affected villi & & \\
Total & 17 & 15 \\
Cases & 602 & 717 \\
Total villi & $18(3.0 \%)$ & $48(6 \cdot 7 \%)$ \\
Affected villi & &
\end{tabular}

obtain tissue. Pyloroplasty preceded by biopsy was done in eight of the 10 patients with duodenal ulcer, two of the four with pyloric ulcer, and in none of the eight with gastric ulcer, the remaining patients in these groups having partial gastrectomies. In five of the 10 patients with carcinoma specimens were taken by biopsy before various operations, and in the remainder they were taken after resection. In the duodenal ulcer group, therefore, there was a predominance of small biopsy specimens, which is reflected in the smaller number of villi counted in the sections from this group.

Although the delay and trauma associated with resection might be expected to cause mucosal changes, the evidence is against its having done so. The most severe changes were seen in the biopsies from patients with duodenal ulcer, while many of the strips cut from tissue resected for gastric ulcer 
showed normal mucosa. It is inconceivable that direct biopsy preceded only by opening the duodenum should have led to inflammatory or other changes which would not have been caused in greater degree by duodenal clamping and transection.

OTHER MUCOSAL ABNORMALITIES There was a variable amount of cellular infiltration of the lamina propria, and lymph follicles were occasionally seen. Because of Patzelt's case mentioned above, particular attention was paid to a possible association of lymph follicles with abnormal epithelium but none was found, nor was there any correlation of intensity of cellular infiltration with the presence of gastric cells.

ZOLLINGER-ELLISON SYNDROME Through the kindness of Mr. J. H. L. Ferguson and Dr. R. E. Cotton of the Middlesex Hospital it has been possible to examine a nodule taken at operation from a patient in whom a pancreatic islet cell tumour was subsequently found at necropsy. The patient had steatorrhoea and recurrent severe haemorrhages, and her fasting gastric contents had an acidity of $111 \mathrm{mEq}$./litre. The nodule was found when the second part of the duodenum was opened. It consisted of a sessile mass of Brunner's glands about $1 \mathrm{~cm}$. in diameter in the fixed state, and covered with epithelium which is largely but not entirely gastric in type: photomicrographs of it are shown in Figures 7 and 8. The villi are stunted and their surfaces are almost uniformly covered with gastric epithelium which is best developed near their summits. Some of the cells are completely filled with P.A.S.-staining material (Fig. 8). Mitoses are scanty and can only be found in the short junctional region between the crypts and Brunner's glands. There is no inflammatory infiltrate. This polyp presents in extreme form the epithelial abnormality described in this paper.

\section{DISCUSSION}

When a tissue is found to be partly composed of cells which are normally foreign to it the explanation most often lies in heterotopia or metaplasia, that is, in a developmental or an acquired abnormality of differentiation. If intestinal epithelium were renewed by mitotic division of its cells at random, a patch of abnormal cells could be attributed to metaplasia. But it is now known (Leblond and Stevens, 1948; Bertalanffy and Nagy, 1961; Creamer, Shorter, and Bamforth, 1961) that intestinal epithelium is regenerated by division only in the crypts, and that the cells migrate up the sides of the villi to their tips, where they are lost either by shedding or by lysis. Turnover is rapid, the life of a single cell being about two and a half days. The gastric epithelial cells found in the intestine must behave in the same way, because no mitoses were found among them. The appearance of such cells near the tips of villi means that they have been formed by alteration of adult intestinal cells, or alternatively that they, too, were formed in the crypts and migrated as do normal cells.

Taking the former possibility first, an intestinal cell could be transformed into a gastric cell by losing the specialized structures concerned with absorption, namely, the brush border and the large mitochondria adjacent to it, and becoming filled with a mucous droplet. The whole process has the appearance of being a de-differentiation in which the absorptive function is sacrificed to an overriding defensive need. If this interpretation is correct it would be reasonable to assume that excessive and sustained acidity is the stimulus which provokes this cellular response, and many of the facts recorded in this paper support such a suggestion. The change is best developed in those parts of the epithelial surface most exposed to the intestinal contents, namely the summits of the villi (Fig. 7) and over polyps (Fig. 6). Further, the prevalence of gastric epithelium has been found to increase in the sequence: gastric ulcer or cancer; pyloric ulcer; duodenal ulcer. It is well known that gastric acidity increases in the same sequence; duodenal acidity does also (Atkinson and Henley, 1955). The argument would be greatly strengthened if it could be extended to patients with Zollinger-Ellison syndrome whose gastric and duodenal (Summerskill, 1959; Rawson, England, Gillam, French, and Stammers, 1960) acidities are highest of all. In the absence of comparable histological material from such patients there is suggestive evidence from the case of James (1963) and from the single case recorded here that gastric epithelium is more prominently developed in the ZollingerEllison syndrome than it is in ordinary duodenal ulcer.

An experiment described by Florey et al. (1939) supports the argument being put forward here. These authors made a fistula from the duodenum and attached it to a Pavlov pouch in a pig. After nine months the animal was killed and the fistula studied histologically; many of the villi were now covered with columnar cells similar to those which line the stomach. Although such cells were found in scattered villi of the duodenum of the normal pig, they were much less extensive than in the experimental material. In this experiment it may be presumed that the duodenal fistula was exposed to unusually high acidity, and that the observation, so far an isolated one, is an experimental counterpart to the fact of human pathology which is here described. 
This explanation of misplaced gastric epithelium, that it is intestinal epithelium which has lost absorptive structure and function in the face of adverse conditions, requires that the response were cellular and would occur cell by cell at random. These cells are, however, never found in isolation. If, therefore, the change is induced in adult intestinal cells it must be by some means which affects a group of them together, through the agency perhaps of an induced change in the basement membrane or lamina propria. Another difficulty is the rapidity with which the change would have to occur; if the entire progress of an intestinal cell from its origin in the crypt to its dissolution at the villous tip only takes two and a half days, the time which it spends in the area where gastric cells are found can only be a few hours.

These objections cannot be made against the alternative hypothesis that gastric cells are formed as such rather than by degeneration of intestinal cells. That they might be so formed in response to injury is suggested by the experiments of Florey and Harding (1935) in which squares of mucosa were removed from the upper duodenum of cats which were later killed at intervals to allow the process of repair to be studied. From the seventh to the 102nd day gastric epithelium was found in the healing defect; at 21 days almost all the epithelium was of this type. There was abrupt demarcation between gastric and duodenal epithelium; no gastric glands appeared.

The villous atrophy with which gastric cells are often associated might be cited as evidence of mucosal injury, and these cells sometimes occur on inflammatory polyps, although it has not been possible to correlate their appearance with other evidence of inflammation and they may occur without it. These observations do not exclude the possibility that the appearance of gastric epithelium is a response to duodenal injury: however, in the case of the Zollinger-Ellison syndrome, where gastric epithelium was most completely developed, signs of inflammation or injury were absent.

Whether acid, injury, or a combination of the two be the stimulus to the appearance of gastric epithelium in the duodenum, it is established that the anomaly is not rare, and that it is not a heterotopia or metaplasia in the usual sense. The adjective 'gastric' cannot be universally applied to these cells; they acquired the name because they usually line the stomach, but they do not always do so, and consideration of the circumstances in which they are replaced in the stomach may lead to an understanding of the reasons for their appearance in the duodenum.

There are two kinds of epithelial cells normally foreign to it which may appear in the stomach. One is the intestinal cell, which is accompanied by goblet and Paneth cells, and which occurs in islands which resemble normal intestinal mucosa, although villi are not well developed. Magnus (1937) showed that such intestinal metaplasia is commoner in gastric ulcer than in duodenal ulcer, and it is commoner still in Addisonian anaemia. It might therefore be supposed that it is liable to appear when gastric acidity is low, although Ball and James (1961) were unable to show any association between intestinal metaplasia and gastric acidity among patients with gastric ulcer.

The other abnormality of gastric epithelium is quantitative rather than qualitative, consisting of partial or complete loss of the intracellular droplet of mucigen so that, in the extreme case, the cell becomes cuboidal and lacks any distinguishing histological characteristics: multiple layering of such cells is common. This abnormality is also commoner in gastric ulcer, particularly in those patients whose gastric contents become neutral at night (Ball and James, 1961). There is therefore some reason for supposing that normal gastric epithelium tends not to be maintained when the gastric contents are weakly acid or anacid; by contrast, when gastric acidity is high, as in duodenal ulcer, the gastric cells are unusually tall and well filled with mucigen. Similarly in the duodenum, normal conditions of acidity allow intestinal epithelium to predominate; when acidity is high and periods of neutrality short or absent gastric epithelium tends to appear.

It would, however, be going too far to say that the nature of the epithelium lining either the stomach or the duodenum is entirely determined by the conditions of acidity prevailing. Two pieces of evidence can be cited against such an extreme hypothesis; first in Addisonian anaemia, where anacidity has been complete for years, normal gastric epithelium is still found and is sometimes extensive, even though much of the stomach is lined by intestinal or degenerate epithelium. Second, a search for gastric epithelium in the jejunum in the neighbourhood of stomal ulcers following gastroenterostomy has failed to reveal any. It therefore seems likely that anatomical site is a determinant of epithelial type in the upper alimentary tract, gastric epithelium appearing and remaining most easily in the stomach where it is native, and less readily at sites further down the intestine: but epithelial cell type also depends on environmental as well as anatomical factors.

It has been suggested above that the epithelial change is a protective one; Florey et al. (1939) made the same suggestion in considering the implications of their experiment. The change is not extensive 
enough in ordinary duodenal ulcer to provide effective protection; $85 \%$ of the villi are still covered by intestinal epithelium. It remains for further work to show whether gastric epithelium is more prevalent in the duodenum of subjects without ulcer; its greater prevalence in women may play a part in the relative immunity of that sex from duodenal ulcer.

The strongest evidence that gastric epithelium has protective properties comes from the ZollingerEllison syndrome, one of whose features is the tendency for ulceration to develop distal to the usual site, either low in the duodenum or in the jejunum. Thus of 30 ulcers in 24 patients described by Ellison (1956), six were in the second part of the duodenum, three in the third part, and four in the jejunum. Zollinger and Elliott (1959) described two patients with perforating jejunal ulcers; intestinal malabsorption caused by jejunal ulceration is now a wellrecognized part of this syndrome (Summerskill, 1959), although it can be caused by other mechanisms (Telling and Smiddy, 1961).

It may be that the upper duodenum in these cases owes its immunity to protection by epithelium of the kind illustrated in Figs. 7 and 8, whose development at the expense of intestinal epithelium has been provoked by the high and continuous acidity found in the duodenum. In ordinary duodenal ulcer the duodenum is only intermittently acid (Atkinson and Henley, 1955), so that peptic ulceration occurs at sites where acidity alternates with neutrality, as it does in the stomach in gastric ulcer (James and Pickering, 1949; Watkinson, 1951; Ball, 1961); areas kept continuously acid, such as the stomach in duodenal ulcer and the upper duodenum in the Zollinger-Ellison syndrome, are protected from ulceration by the continuous intracellular mucous barrier which the acid promotes or preserves.

\section{SUMMARY}

The epithelium of the first part of the duodenum has been examined in freshly fixed mucosal specimens obtained at operation.

Islands of gastric cells were common in patients with duodenal ulcer, less so in patients with pyloric ulcer, and rare in patients with ulcer of the body of the stomach or with gastric cancer.

Whatever the diagnosis, gastric cells were more prevalent in women than in men, and they were more often found on stunted villi.

A polyp from the second part of the duodenum of a patient with the Zollinger-Ellison syndrome was covered with well-developed gastric epithelium.

It is suggested that 'gastric' epithelium appears when duodenal acidity is high and that it is resistant to ulceration. The anomaly mirrors the degeneration of the mucosa of the stomach which accompanies low gastric acidity.

I am gratefully indebted to surgical colleagues who took the biopsies; to Mr. J. H. L. Ferguson and Dr. R. E. Cotton for material from the case of the ZollingerEllison syndrome; to Professor J. Gough and his staff for preparing the sections; and to Mr. R. Marshall for the photomicrographs.

\section{REFERENCES}

Aronson, A. R., and Norfleet, R. G. (1962). The duodenal mucosa in peptic ulcer disease. A clinical pathological correlation. Amer. J. dig. Dis., 7, 506-514.

Atkinson, M., and Henley, K. S. (1955). Levels of intragastric and intraduodenal acidity. Clin. Sci., 14, 1-14.

Ball, P. A. J. (1961). The secretory background to gastric ulcer. Lancet, 1, 1363-1365.

—, and James, A. H. (1961). The histological background to gastric ulcer. Ibid., 1, 1365-1367.

Bertalanffy, F. D., and Nagy, K. P. (1961). Mitotic activity and renewal rate of the epithelial cells of human duodenum. Acta anat. (Basel), 45, 362-370.

Creamer, B., Shorter, R. G., and Bamforth, J. (1961). The turnover and shedding of epithelial cells. Gut, 2, 110-116.

Doniach, I., and Shiner, M. (1957). Duodenal and jejunal biopsies. II. Histology. Gastroenterology, 33, 71-86.

Ellison, H. (1956). The ulcerogenic tumor of the pancreas. Surgery, 40, 147-170.

Florey, H. W., and Harding, H. E. (1935). The healing of artificial defects of the duodenal mucosa. J. Path. Bact., 40, 211-218.

_- Jennings, M. A., Jennings, D. A., and O'Connor, R. C. (1939). The reactions of the intestine of the pig to gastric juice. Ibid., $49,105-123$.

James, A. H. (1963). Gastric epithelium in the duodenum of a patient with gastric hyperacidity. Proc. 2nd wld Congr. Gastroentero$\log y, 2,540-543$.

- and Pickering, G. W. (1949). The role of gastric acidity in the pathogenesis of peptic ulcer. Clin. Sci., 8, 181-210.

Leblond, C. P., and Stevens, C. E. (1948). The constant renewal of the intestinal epithelium in the albino rat. Anat. Rec., 100, 357-371.

Magnus, H. A. (1937). Observations on the presence of intestinal epithelium in the gastric mucosa. J. Path. Bact., 44, 389-398.

Patzelt, V. (1936). Darm. In W. v. Möllendorff's Handbuch der Mikroskopischen Anatomie des Menschen, Bd. V, Teil 3. Springer, Berlin.

Puhl, H. (1927). Die Veränderungen der Duodenalschleimhaut beim Ulcusleiden. Virchows Arch. path. Anat., 265, 160-198.

Rawson, A. B., England, M. T., Gillam, G. G., French, J. M., and Stammers, F. A. R. (1960). Zollinger-Ellison syndrome with diarrhoea and malabsorption. Observations on a patient before and after pancreatic islet-cell tumour removal without resort to gastric surgery. Lancet, 2, 131-134.

Shiner, M. (1957). Duodenal and jejunal biopsies. I. A discussion of the method, its difficulties and applications. Gastroenterology, 33, 64-70.

Summerskill, W. H. J. (1959). Malabsorption and jejunal ulceration due to gastric hypersecretion with pancreatic islet-cell hyperplasia. Lancet, 1, 120-123.

Taylor, A. L. (1927). The epithelial heterotopias of the alimentary tract. J. Path. Bact., 30, 415-449.

Teliing, M., and Smiddy, F. G. (1961). Islet tumours of the pancreas with intractable diarrhoea. Gut, 2, 12-17.

Watkinson, G. (1951). A study of the changes in $p H$ of gastric contents in peptic ulcer using the twenty-four hour test meal. Gastroenterology, 18, 377-390.

Zollinger, R. M., and Elliott, D. W. (1959). Pancreatic endocrine function and peptic ulceration. Gastroenterology, 37, 401-411. 